Article

\title{
Sinusoidal Oscillators Operating at Frequencies Exceeding Unity-Gain Bandwidth of Operational Amplifiers
}

\author{
Vladimir Ulansky ${ }^{1, *([)}$ and Ahmed Raza ${ }^{2}$ (I) \\ 1 Department of Electronics, Robotics, Monitoring and IoT Technologies, National Aviation University, \\ 03058 Kyiv, Ukraine \\ 2 Projects and Maintenance Section, The Private Department of the President of the United Arab Emirates, \\ Abu Dhabi 000372, UAE; ahmed.awan@dopa.ae \\ * Correspondence: vladimir_ulansky@nau.edu.ua
}

Received: 26 April 2020; Accepted: 17 May 2020; Published: 20 May 2020

\begin{abstract}
This paper proposes a novel operational amplifier (OPA) voltage-controlled oscillator (VCO) circuits on the basis of impedance converters. The VCO can operate over a frequency range exceeding unity-gain bandwidth due to the location of the tank circuit, not at the output of the OPA, but at the noninverting input. The paper presents the mathematical modeling of oscillated amplitude and start-up conditions. The simulation results confirm the theoretical achievements. The designed and simulated VCO uses an ultra-low noise wideband OPA LMH6629MF, covers a frequency band between $0.830 \mathrm{GHz}$ and $1.429 \mathrm{GHz}$, and exhibits a maximum in-band total harmonic distortion (THD) of $1.7 \%$. It has a maximum in-band phase noise of $-139.3 \mathrm{dBc} / \mathrm{Hz}$ at $100 \mathrm{kHz}$ offset frequency and has an outstanding value of a standard figure of merit $(\mathrm{FoM})$ of $-198.6 \mathrm{dBc} / \mathrm{Hz}$. The zero-peak amplitude of output voltage is from $3.2 \mathrm{~V}$ to $4 \mathrm{~V}$ for all generated frequencies at a supply voltage of $\pm 5 \mathrm{~V}$. The fabricated prototype-oscillator based on OPA LMH6624 operates at a frequency of $583.1 \mathrm{MHz}$ with a power level of $0 \mathrm{dBm}$.
\end{abstract}

Keywords: operational amplifier; voltage-controlled oscillator; unity-gain bandwidth; varactor; total harmonic distortion; phase noise

\section{Introduction}

Sinusoidal oscillators are used in almost all systems of receiving and transmitting information, as well as in measuring instruments and systems. One of the most rapidly developing class of sinusoidal oscillators is the class of the voltage-controlled oscillator (VCO). Voltage-controlled oscillators are commonly used in digital frequency synthesizers, which are one of the main subsystems of modern communications systems. The rapid development of modern communications and instrumentation systems has created a high demand for low noise VCOs [1-3]. Modern microwaves sinusoidal oscillators use bipolar junction transistors (BJT), heterojunction bipolar transistors (HBT), a low-noise high-electron-mobility-transistors (HEMT) and pseudomorphic HEMT (pHEMT) as active devices for achieving low phase-noise performance [4-6]. The appearance on the market of a ultra-low-noise, high-speed, broadband operational amplifier (OPA) creates the possibility of their use in the sinusoidal oscillators in the ultra-high frequency range. For example, the LMH6629MF (Texas Instruments) OPA has an input noise voltage of $0.69 \mathrm{nV} / \sqrt{ } \mathrm{Hz}$ at the corner frequency of $4 \mathrm{kHz}$, a slew rate of $1600 \mathrm{~V} / \mu \mathrm{s}$ and small-signal $-3 \mathrm{~dB}$ bandwidth of $900 \mathrm{MHz}$ [7]. Low-noise, high-speed OPA oscillators can offer a practical alternative to transistor oscillators, the performance of which to some extent depends on the variability of the transistor small-signal parameters. The use of a low-noise, high-speed OPA as 
an active device in the oscillator circuits has some advantages [8,9]. An operational amplifier is an amplifier with very high input impedance and very low output impedance; it is easy to introduce required positive feedback around the OPA; the oscillator design is simple due to the lack of the bias circuit; the oscillator circuit does not require any adjustment during fabrication.

As is well known $[8,10,11]$, oscillators based on the Colpitts and Hartley topology require a relatively high voltage gain to start-up oscillation. High voltage gains reduce the maximum frequency of oscillation because of the limited gain-bandwidth product of OPA. Besides, the maximum frequency of generated sinusoidal oscillations at the output of the OPA in the Colpitts and Hartley topologies is limited by the ratio of the slew rate to the amplitude of voltage oscillations multiplied by two pi [12]. Thus, with the required voltage amplitude of, say, three volts, and the use of the LMH6629 OPA, the maximum achievable frequency will be less than $85 \mathrm{MHz}$, which is very far from the microwave frequency range. By simple calculations, we can estimate what should be the slew rate of an OPA to achieve a frequency of $1 \mathrm{GHz}$ with a $3 \mathrm{~V}$ amplitude of oscillations. It should be about 19,000 V/ $\mathrm{\mu s}$. Currently, such a slew rate in OPA is unattainable.

The VCO topology proposed in [13] uses the OPA circuit with negative input inductance observed at the noninverting input of the OPA. The disadvantage of this circuit is the use of two resistors, one of which presents the positive feedback circuit, and the second connects the inverting input of the OPA to the ground. These resistors are the source of thermal noise.

In this study, we propose several new VCO topologies that use the idea of a negative impedance converter. However, unlike the well-known studies [14-17], the converter circuit does not include resistors. In contrary to the Colpitts and Hartley oscillators requiring a sufficiently high voltage gain for self-excitation, the proposed oscillator circuits operate with a voltage gain of less than unity; this feature significantly increases the operating frequency, which can exceed the unity-gain bandwidth of the OPA. This particularity of the proposed VCO circuits is due to the location of the tank circuit not at the output of the OPA, but at the noninverting input. Mathematical modeling, simulation, and prototype implementation of the proposed oscillators are given.

\section{Architecture of Oscillators}

Figure 1 shows the general VCO electronic diagram. The circuit inside the dashed rectangular is the negative impedance converter. The input impedance observed at the noninverting terminal of the OPA is as follows [16]:

$$
Z_{\text {in }}=-Z_{2} \frac{Z_{1}}{Z_{0}}
$$

where $Z_{\text {in }}$ is the input impedance seen by the noninverting terminal of the OPA, $Z_{0}$ is the impedance between the inverting input and output of the OPA, $Z_{1}$ is the impedance between the noninverting input and output of the OPA, and $Z_{2}$ is the impedance between the inverting terminal of the OPA and ground. The step-by-step derivation of Equation (1) is given in [18] (pp. 349-350).

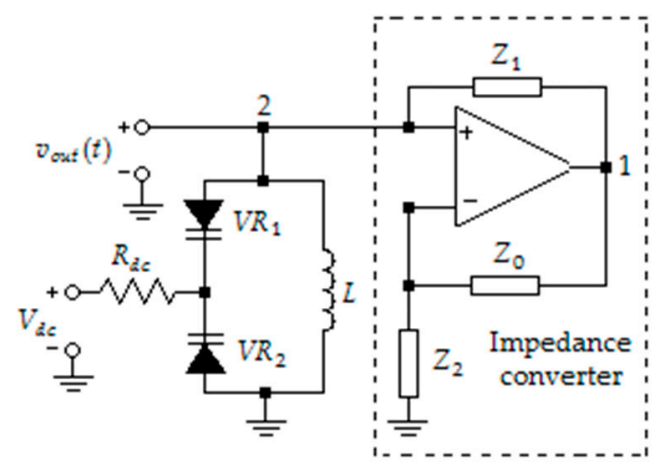

Figure 1. General electronic diagram of voltage-controlled oscillator on the basis of an impedance converter. 
In Reference [15-17], one of the impedances $Z_{0}, Z_{1}$, or $Z_{2}$ is capacitive, and the other two are resistive.

The presence of significant resistances in the circuit of any oscillator leads to an increase in thermal noise [19]; therefore, in this study, the impedances $Z_{0}, Z_{1}$, and $Z_{2}$ are capacitive or inductive.

In the circuit of Figure 1, inductor $L$ and two contrary connected varactors $V R_{1}$ and $V R_{2}$ present the tank circuit of the VCO. Resistor $R_{d c}$ isolates the dc control voltage line from the VCO tank.

As can be seen in Figure 1, the tank circuit is connected to the noninverting input of the OPA rather than its output. This feature of the proposed VCO allows extending operation frequency range beyond the unity-gain bandwidth of OPA.

Figure 2 shows VCO circuits based on impedance converters with two inductors and one capacitor. The circuits in Figure 2a,b introduce positive feedback through inductor $L_{1}$ and capacitor $C_{1}$, respectively.

Figure 3 presents VCO circuits on the base of impedance converters with three inductors (a) and two capacitors and one inductor (b).

The oscillator circuits based on impedance converters in which a capacitor is used between the inverting input of the OPA and ground are not considered.

Further, in the article, we will analyze in detail the VCO circuit presented in Figure 2a, and where necessary, we will refer to other VCO configurations.

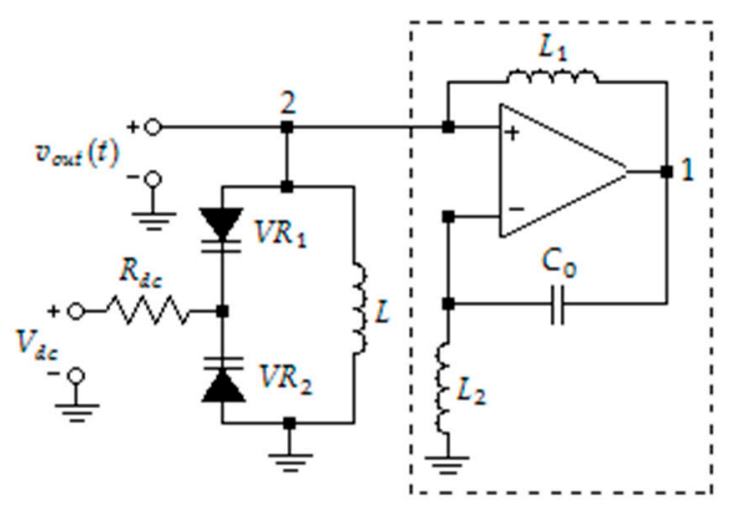

(a)

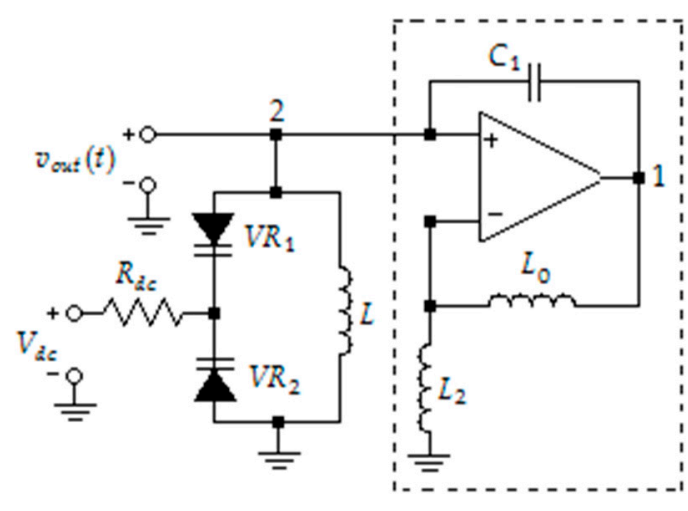

(b)

Figure 2. VCO circuits based on impedance converters with two inductors and one capacitor; (a) with inductive positive feedback and (b) with capacitive positive feedback.

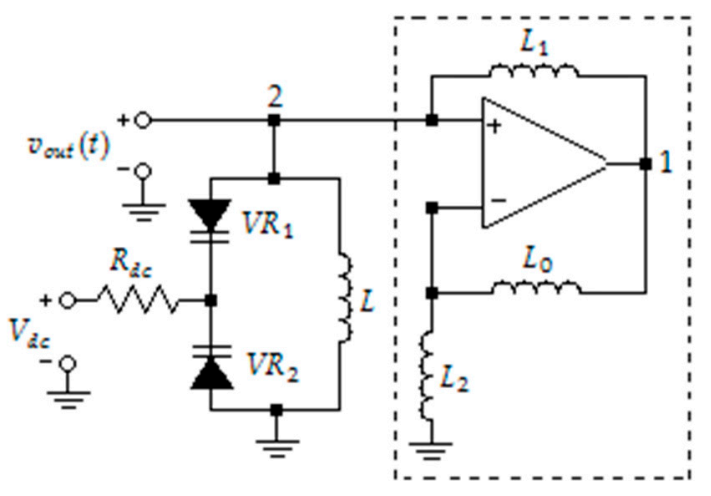

(a)

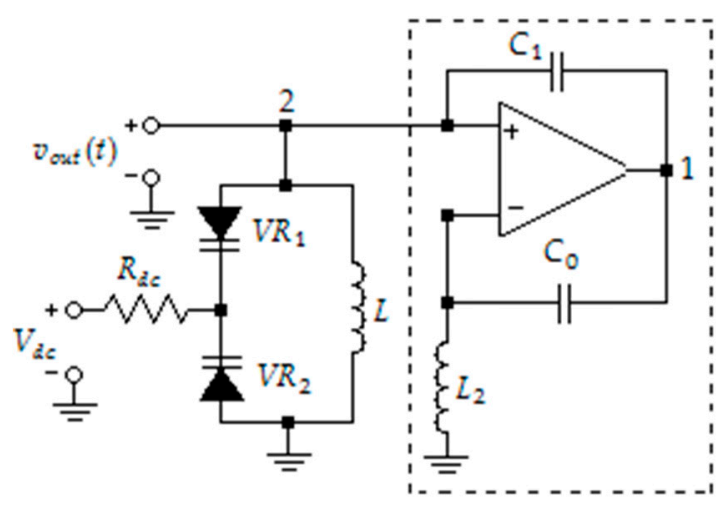

(b)

Figure 3. Voltage-controlled oscillator (VCO) circuits based on the impedance converter with three inductors (a) and one inductor and two capacitors (b). 


\section{Converter Analysis}

Before analyzing the VCO circuit of Figure 2a, let's examine the operation of the converter at frequencies exceeding the OPA bandwidth. Figure 4a shows the test circuit. We assume that the OPA unity-gain bandwidth is $900 \mathrm{MHz}$, the slew rate is $1600 \mathrm{~V} / \mu \mathrm{s}$, the open-loop gain is $1000 \mathrm{~V} / \mathrm{V}$, and the test signal is a sinusoidal voltage with a frequency of $1 \mathrm{GHz}$ and peak amplitude of $2 \mathrm{~V}$.

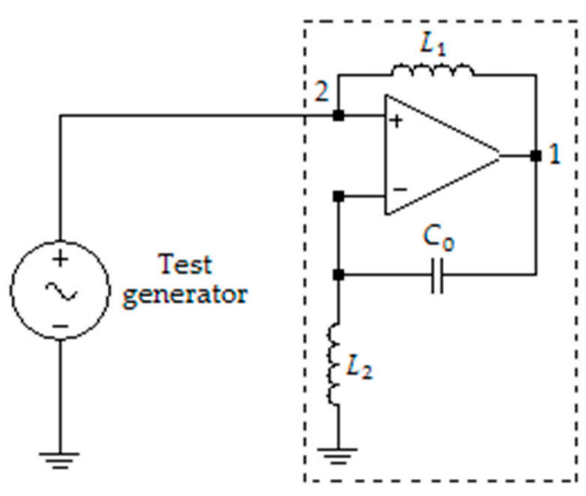

(a)

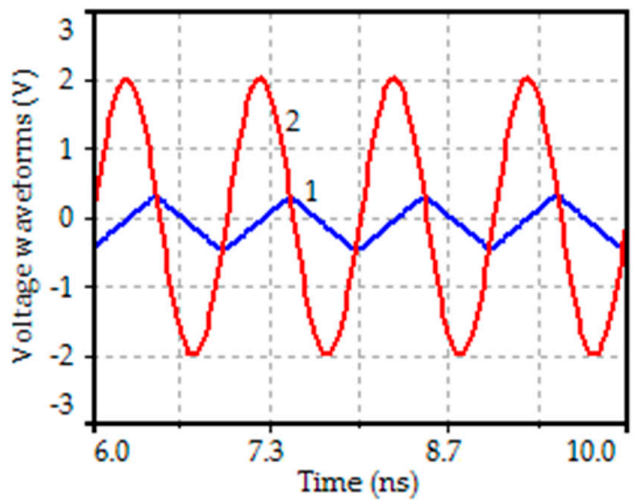

(b)

Figure 4. (a) Impedance converter testing scheme; (b) Input (curve 2) and output (curve 1) voltages of the test circuit.

Figure $4 \mathrm{~b}$ shows the voltage waveforms at the noninverting input (curve 2) and the output of the OPA (curve 1). As we can see in Figure $4 b$, the slew rate of the OPA is not sufficient to ensure the shape of the OPA output voltage as that at the noninverting input. Therefore, we observe a triangular voltage waveform at the OPA output (node 1). Moreover, Figure $4 \mathrm{~b}$ shows that the OPA output voltage lags the input voltage by $90^{\circ}$. From a comparison of the circuits in Figures $2 \mathrm{a}$ and $4 \mathrm{a}$, we can see that instead of the test generator in Figure 4a, a parallel resonant circuit is used in Figure 2a. We will show further that the shape of the voltage curves in the circuit of Figure 2a will be the same as in Figure $4 b$; however, curve 2 will correspond to the voltage at the output of the VCO.

\section{VCO Analysis}

The electronic part of the VCO introduces an alternating current $(\mathrm{ac})$ source $i_{O P A}(t)$ into the tank circuit, as shown in Figure 5, where $C_{V C O}$ and $L_{V C O}$ are, respectively, the VCO total capacitance and inductance, and $R_{\text {par }}$ is the equivalent parallel resistance of the tank circuit at the fundamental frequency. Essentially the current $i_{O P A}(t)$ is the feedback current flowing through inductor $L_{1}$.

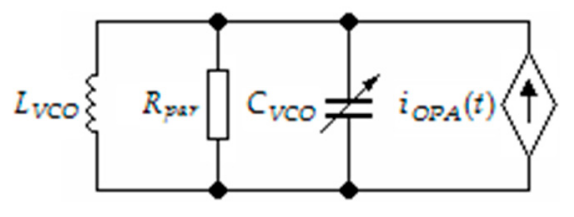

Figure 5. AC equivalent circuit of the VCO.

The VCO total capacitance includes the capacitance of the contrary connected varactors $V R_{1}$ and $V R_{2}$, the input capacitance of the OPA, and the parasitic capacitance of the printed circuit board (PCB). Therefore,

$$
C_{V C O}\left(V_{d c}\right)=\frac{C_{V R 1}\left(V_{d c}\right) C_{V R 2}\left(V_{d c}\right)}{C_{V R 1}\left(V_{d c}\right)+C_{V R 2}\left(V_{d c}\right)}+C_{P C B}+C_{O P A}
$$

As we can see in Equation (2), the VCO capacitance is a function of voltage $V_{d c}$ because the varactor capacitance depends on this voltage. Onwards, inductor $L_{1}$ provides positive shunt-shunt feedback. 
By applying the $y$-parameter analysis to the positive feedback network, we find that $y_{11}$ parameter incorporates into the tank circuit. Since $y_{11}=1 / j \omega_{f u n} L_{1}$, inductance $L_{1}$ appears in parallel with tank inductance $L$, where $\omega_{f u n}$ is the fundamental angular frequency of oscillation.

Therefore, the total VCO tank circuit inductance is given by

$$
L_{V C O}=L_{1} \| L
$$

The current $i_{O P A}(t)$ flows through the tank circuit. However, only the first harmonic of the current flow creates a significant voltage drop across the tank. The second, third, and subsequent current harmonics create insignificant voltage drops that can be neglected.

We should also note that the tank circuit is connected to the noninverting input of the OPA, where the input impedance is extremely high. Therefore, the OPA does not practically short-out the tank circuit.

This property of the proposed VCO allows obtaining high voltage amplitude of the generated voltage $v_{\text {out }}(t)$, which is not limited by the OPA output. Indeed, we can describe the VCO output voltage by the following equation:

$$
v_{\text {out }}(t)=\left|I_{O P A, 1}\left(V_{d c}\right)\right| R_{\text {par }}\left(V_{d c}\right) \sin \left[\omega_{f u n}\left(V_{d c}\right) t+\varphi_{1}\left(V_{d c}\right)\right]
$$

where $\left|I_{O P A, 1}\left(V_{d c}\right)\right|, \omega_{f u n}\left(V_{d c}\right)$, and $\varphi_{1}\left(V_{d c}\right)$ are, respectively, the amplitude, frequency and initial phase of the first harmonic of current $i_{O P A}(t)$. Therefore, we can see from (4) that the amplitude of the generated sinusoidal voltage is proportional to $\left|I_{O P A, 1}\right|$ and $R_{p a r}$. In a virtual case of lossless tank circuit, i.e., when $R_{p a r} \rightarrow \infty$, the amplitude of the output voltage would tend to infinity.

This is a unique property of the proposed OPA oscillator because, for the Colpitts and Hartley OPA oscillators [8], the output amplitude satisfies the following inequality:

$$
V_{m} \leq \frac{4 V_{\text {sat }} R_{\text {par }}}{\pi\left(R_{C}+R_{\text {par }}\right)}
$$

where $V_{\text {sat }}$ is the OPA saturation voltage, and $R_{C}$ is the resistance of the load resistor connected between the OPA output and tank circuit.

Since the OPA saturation voltage in (5) is less than the power supply voltage $V_{c c}$, the oscillation amplitude is also less. Figure 6a illustrates the behavior of the OPA output voltage (curve 1) and the oscillator output voltage (curve 2) for the Colpitts oscillator operating at frequency of $53 \mathrm{MHz}$ with $V_{c c}= \pm 5 \mathrm{~V}$ and voltage peak amplitude of $3.7 \mathrm{~V}$. We can also observe in Figure 6a that the shape of the voltage at the output of the OPA, in this particular case, is trapezoidal, which means the slew rate of the OPA is not high enough to ensure a rectangular shape.

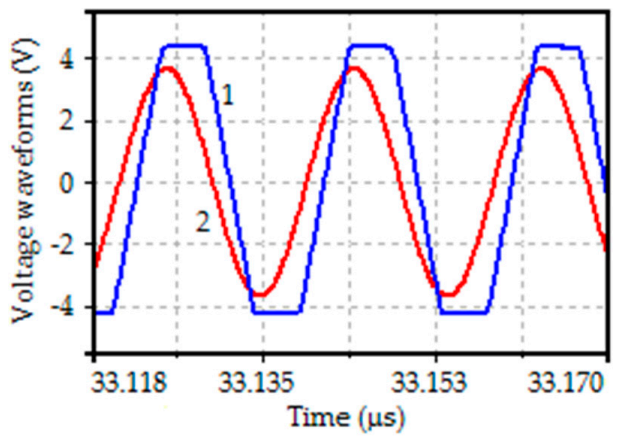

(a)

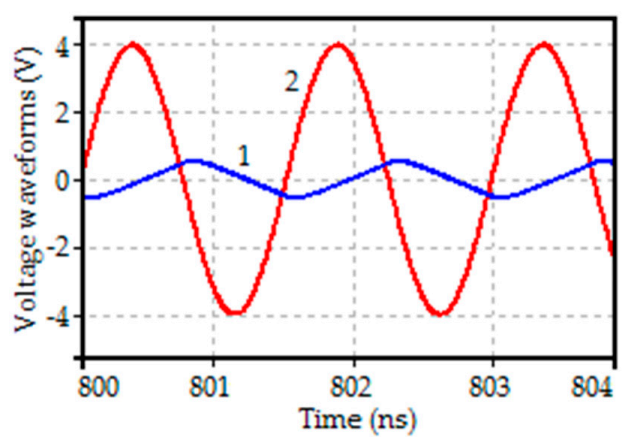

(b)

Figure 6. (a) OPA output voltage (curve 1) and oscillator output voltage (curve 2) for the Colpitts VCO; (b) OPA output voltage (curve 1) and oscillator output voltage (curve 2) for the proposed VCO. 
With a further increase in the frequency of the generated oscillations in the Colpitts oscillator, the voltage shape at the output of the OPA becomes triangular with the amplitude less than $V_{\text {sat }}$. In this case, also, the amplitude of sinusoidal oscillations in the Colpitts oscillator will always be less than the magnitude of triangular oscillations.

A completely different relationship exists between the amplitudes of the voltages at the output of the OPA (node 1) and the oscillator (node 2) in the circuit in Figure 2a. Figure 6b illustrates the behavior of the OPA output voltage (curve 1) at node 1 and the oscillator output voltage (curve 2) at node 2 for the proposed oscillator operating at frequency of $667 \mathrm{MHz}$ with the same OPA, power supply voltages and output peak amplitude of $4 \mathrm{~V}$. As can be seen in Figure $6 \mathrm{~b}$, the amplitude of the sinusoidal voltage can be much larger than the voltage amplitude at the output of the OPA (node 1).

Therefore, the proposed VCO can operate at frequencies significantly exceeding the unity-gain bandwidth of OPA.

It should also be noted that by choosing a low-noise OPA, the phase noise of the VCO will be determined mainly by the noise of the tank circuit.

\section{Amplitude of Oscillations}

Let us determine the amplitude of the sinusoidal voltage at the output of the VCO (node 2). Assume the voltage at node 1 be triangular, as shown in Figure $6 \mathrm{~b}$ (curve 1). For the triangle wave, we can describe the voltage at node 1 by the complex exponential Fourier series as follows:

$$
v_{O P A}(t)=0.5 \sum_{\mu=-\infty}^{\infty} V_{\mu} \mathrm{e}^{j \mu \omega_{f u n} t}
$$

where $V_{\mu}$ is the complex amplitude of the harmonic number $\mu$ of voltage $v_{O P A}(t)$.

The complex amplitude $V_{\mu}$ can be represented as

$$
V_{\mu}=\left|V_{\mu}\right| \mathrm{e}^{j \theta_{\mu}}
$$

where $\left|V_{\mu}\right|$ and $\theta_{\mu}$ are the amplitude and phase of the voltage harmonic number $\mu$, respectively.

As is well known [20], the amplitude of the voltage harmonic $\mu$ for the triangle wave is

$$
\left|V_{\mu}\right|=\frac{8 V_{\text {triangle }}}{\pi^{2} \mu^{2}} \sin \frac{\mu \pi}{2}
$$

where $V_{\text {triangle }}$ is the amplitude of the triangular voltage at the OPA output.

The feedback current $i_{O P A}(t)$, which flows from node 1 into the tank circuit, we also present by the complex exponential Fourier series

$$
i_{O P A}(t)=0.5 \sum_{\mu=-\infty}^{\infty} I_{O P A, \mu} \mathrm{e}^{j \mu \omega_{f u n} t}
$$

where $I_{O P A, \mu}$ is the complex amplitude of the current harmonic number $\mu$.

The complex amplitude $I_{O P A, \mu}$ we write in polar form as follows:

$$
I_{O P A, \mu}=\left|I_{O P A, \mu}\right| \mathrm{e}^{j \varphi_{\mu}}
$$

where $\left|I_{O P A, \mu}\right|$ and $\varphi_{\mu}$ are the amplitude and phase of the current harmonic number $\mu$, respectively.

In the ac equivalent circuit of the VCO shown in Figure 5, the feedback inductor $L_{1}$ is in parallel with tank inductor $L$. The feedback current $i_{O P A}(t)$ flows through inductor $L_{1}$ and tank circuit due to the applied voltage $v_{O P A}(t)$. Considering the forward transfer admittance of the feedback network 
$y_{12}=-1 / j \omega_{f u n} L_{1}$ and parallel connection of inductors $L_{1}$ and $L$ in the equivalent circuit of Figure 5, by Ohm's law, we have

$$
I_{O P A, \mu}=-V_{\mu} /\left(j \omega_{f u n} L_{1} \| L\right)=j V_{\mu} /\left(\omega_{f u n} L_{1} \| L\right)
$$

By substitution of (7) and (8) into (11), we get

$$
I_{O P A, \mu}=\frac{8 V_{\text {triangle }}}{\omega_{f u n} L_{1} \| L \pi^{2} \mu^{2}} \sin \frac{\mu \pi}{2} \exp \left[j\left(\theta_{\mu}+\frac{\pi}{2}\right)\right]
$$

The first harmonic of current $i_{O P A}(t)$ is of interest because for the higher harmonics, the equivalent resistance of the tank circuit is negligible, and they do not create a significant voltage drop. By substitution $\mu=1$ into (12) gives

$$
I_{O P A, 1}=\frac{8 V_{\text {triangle }}}{\omega_{f u n} L_{1} \| L \pi^{2}} \exp \left[j\left(\theta_{1}+\frac{\pi}{2}\right)\right]
$$

We determine the first harmonic of the voltage across the tank by multiplying the complex amplitude $I_{O P A, 1}$ and the equivalent resistance of the tank at resonance $R_{p a r}$ as follows:

$$
V_{\text {out }, 1}=\frac{8 V_{\text {triangle }} R_{\text {par }}}{\omega_{\text {fun }} L_{1} \| L \pi^{2}} \exp \left[j\left(\theta_{1}+\frac{\pi}{2}\right)\right]
$$

By comparing (7) when $\mu=1$ and (14), we can state that the first harmonic of voltage across the tank leads the first harmonic of triangular voltage at the OPA output by $90^{\circ}$, which is confirmed by Figure $6 b$.

From (14) it follows that the amplitude of the voltage across the tank is

$$
\left|V_{\text {out }, 1}\right|=\frac{8 V_{\text {triangle }} R_{\text {par }}}{\omega_{\text {fun }} L_{1} \| L \pi^{2}}
$$

Analyzing (15), we can observe that the amplitude of the VCO output voltage $\left|V_{\text {out }, 1}\right|$ is directly proportional to resistance $R_{\text {par }}$ and inversely proportional to inductance $L_{1} \| L$. As already indicated in the analysis of Equation (4), when using a tank circuit with low losses, the voltage amplitude at the output of the VCO can be significant.

Let us simplify (15) by considering the case when $L_{1}>L$. In this case, $L_{1} \| L \approx L$ and we can write Equation (15) in the following form:

$$
\left|V_{\text {out }, 1}\right|=\frac{8 V_{\text {triangle }} R_{\text {par }}}{\omega_{\text {fun }} L \pi^{2}}
$$

At resonance we have

$$
\omega_{f u n} L=\sqrt{\frac{L}{C_{V C O}}}=\rho
$$

where $\rho$ is the tank circuit characteristic impedance.

As is well known [21] (p. 909), the equivalent resistance of the parallel tank at resonance is

$$
R_{p a r}=\frac{\rho^{2}}{r_{s}}
$$

where $r_{s}$ is the series loss resistance of the tank circuit. 
Substituting (17) and (18) into (16) gives

$$
\left|V_{\text {out }, 1}\right|=\frac{8 V_{\text {triangle }} \rho}{r_{s} \pi^{2}}
$$

Since the ratio of $\rho$ to $r_{S}$ in (19) is equal to the quality factor of the parallel tank circuit $(Q)$, then we write (19) in the following form:

$$
\left|V_{\text {out }, 1}\right|=\frac{8 V_{\text {triangle }} Q}{\pi^{2}}
$$

We derived Equation (20) under the condition of an ideal OPA with infinite input resistance, which does not load the tank circuit. However, in the real OPA, the input resistance is not infinite; therefore, in (20), we should use the loaded quality factor. Therefore,

$$
\left|V_{\text {out }, 1}\right|=\frac{8 V_{\text {triangle }} Q_{L}}{\pi^{2}}
$$

where $Q_{L}$ is the quality factor of the loaded VCO tank circuit.

For the VCO shown in Figure 2b, following the same analysis as for the circuit of Figure 2a, we obtain that the amplitude of oscillations is

$$
\left|V_{\text {out }, 1}\right|=\frac{8 V_{\text {triangle }} \omega_{f} C_{V C O} \| C_{1} R_{\text {par }}}{\pi^{2}}=\frac{8 V_{\text {triangle }} \omega_{f}\left(C_{V C O}+C_{1}\right) R_{\text {par }}}{\pi^{2}}
$$

From the analysis of Equation (22), it follows that the capacitance of the positive feedback capacitor $C_{1}$ should be much less than the capacitance $C_{V C O}$; in this case, the capacitance $C_{1}$ will not affect the frequency of generated oscillations.

Given that at the resonant frequency

$$
\omega_{f}\left(C_{V C O}+C_{1}\right)=\frac{1}{\rho}
$$

We transform Equation (22) as follows:

$$
\left|V_{\text {out }, 1}\right|=\frac{8 V_{\text {triangle }} R_{\text {par }}}{\pi^{2} \rho}
$$

Considering that $R_{\text {par }} / \rho=Q$ in (24), we obtain again Equation (20), which transforms to (21) due to the loaded tank circuit.

The amplitude of the generated sinusoidal voltages in the VCO circuits in Figure $3 a, b$ is also calculated by Equation (21).

\section{VCO Start-Up Conditions}

According to the Barkhausen criteria [22], to provide the sustained oscillations, the following conditions must have a place:

$$
\begin{gathered}
|A||\beta|=1 \\
\varphi_{A}+\varphi_{\beta}=0
\end{gathered}
$$

where $|A|$ and $|\beta|$, and $\varphi_{A}$ and $\varphi_{\beta}$ are, respectively, the gains and initial phases of impedance converter and feedback network.

As shown in Figure $4 \mathrm{~b}$, the voltage gain of the impedance converter is less than unity. We determine the feedback network ratio as follows:

$$
|\beta|=\frac{\left|V_{\text {out }, 1}\right|}{\left|V_{1}\right|}
$$


where $\left|V_{1}\right|$ is the voltage amplitude of the first harmonic of triangular voltage at the output of the OPA (node 1).

Substituting (8) at $\mu=1$ and (21) into (27) gives

$$
|\beta|=Q_{L}
$$

We can conclude from (25) and (28) that at the steady-state the gain of the impedance converter is

$$
|A|=\frac{1}{|\beta|}=\frac{1}{Q_{L}}
$$

To start the oscillations, the product of $|A|$ and $|\beta|$ is made higher than unity, and when the amplitude reaches a constant value $\left|V_{\text {out }, 1}\right|$, this product becomes equal to unity.

From relations (28) and (29), it follows that in the proposed oscillators, the feedback network coefficient $|\beta|$ is more than unity, and the gain of the active network $|A|$ is less than unity; this is a unique property because in the Colpitts and Hartley oscillators the opposite is true, i.e., $|A|>1$ and $|\beta|<1$. Due to this property, the proposed VCO can operate at frequencies significantly exceeding the unity-gain bandwidth of an OPA with sufficiently large oscillation amplitudes.

\section{Simulation and Discussion}

The circuit of Figure 2a was simulated with the help of Multisim (ed. 14.1) using SPICE models of a real OPA, varactors, and RF coil to confirm the operation efficiency of the proposed VCO topology. We selected ultra-low noise, high-speed OPA LMH6629MF with $-3 \mathrm{~dB}$ bandwidth of $900 \mathrm{MHz}$, slew rate of $1600 \mathrm{~V} / \mu \mathrm{s}$, input voltage noise of $0.69 \mathrm{nV} / \sqrt{\mathrm{Hz}}$, and power supply voltage $\pm 5 \mathrm{~V}$. We also selected UHF varactors BB215 and a $3.3 \mathrm{nH}$ RF coil. The other component values are as follows: $L_{1}=L_{2}=1 \mu \mathrm{H}$, $C=100 \mathrm{nF}$, and $R_{d c}=1 \mathrm{k} \Omega$.

Figure 7 shows the simulated VCO schematic with chosen component values.

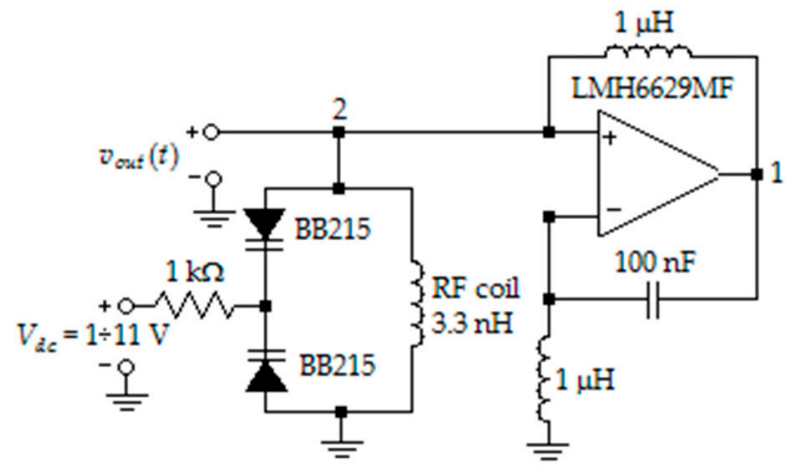

Figure 7. Simulated VCO schematic with indicated component values.

Figure 8 shows the VCO start-up voltage in the interval 0-720 ns at $V_{\mathrm{dc}}=1 \mathrm{~V} \mathrm{(a)}$ and $V_{d c}=11 \mathrm{~V}$ (b). As we can see in Figure 8, the oscillations reach the steady-state condition within $500 \mathrm{~ns}$ at $V_{d c}=1 \mathrm{~V}$ and $50 \mathrm{~ns}$ at $V_{d c}=11 \mathrm{~V}$. Thus, the starting time of $\mathrm{VCO}$ is speedy.

Figure 9 shows the steady-state voltage waveforms at nodes 1 and 2 when $V_{d c}=1 \mathrm{~V}$ (a) and $V_{d c}=11 \mathrm{~V}(\mathrm{~b})$. As can be seen in Figure 9, the amplitude of the triangular voltage at the output of OPA (node 1) is much less than the amplitude of the sinusoidal voltage at the VCO output (node 2).

From the simulation results shown in Figure 9, it is observed that the THD is $1.5 \%$ at $V_{d c}=1 \mathrm{~V}$ and $1.7 \%$ at $V_{d c}=11 \mathrm{~V}$, which corresponds to $-36.5 \mathrm{~dB}$ and $-35.4 \mathrm{~dB}$, respectively.

Since in the microwave frequency range, the THD value of $-30 \mathrm{~dB}$ is considered quite well [23] (p. 291), [24], we can argue that the designed VCO is a low-distortion oscillator. 
Let us check Equation (21). From Figure 9a it can be observed that $V_{\text {triangle }}=0.37 \mathrm{~V}$ and $\left|V_{\text {out }, 1}\right|=3.19 \mathrm{~V}$. To find the loaded quality factor $Q_{L}$, we use the property of the parallel tank circuit that the current circulating in the tank circuit $I_{\text {tank }}$ in $Q_{L}$ times higher than the current in the general circuit $I_{\text {res }}$ [21] (p. 911).

Figure 10a illustrates the location of currents $I_{\text {tank }}$ and $I_{\text {res }}$ in the VCO tank circuit.

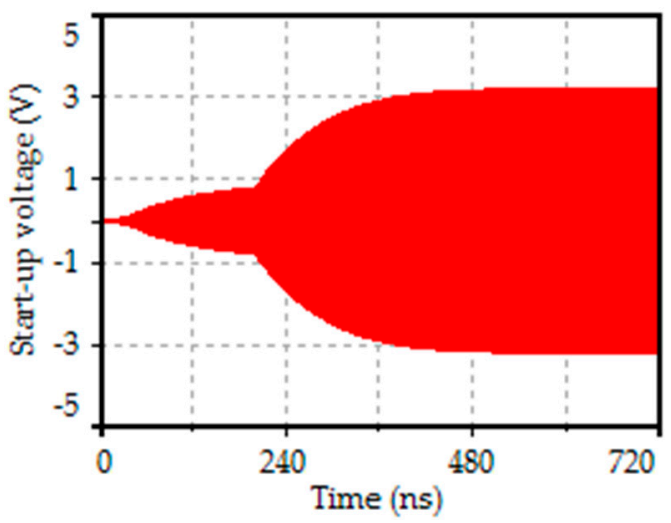

(a)

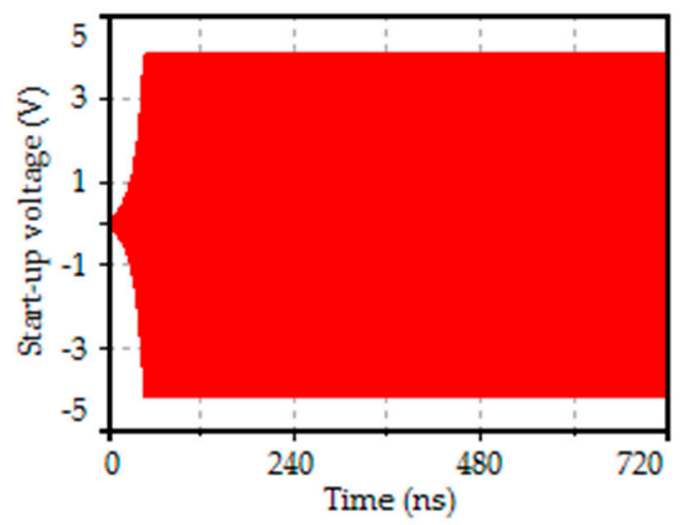

(b)

Figure 8. VCO start-up voltage (a) when $V_{d c}=1 \mathrm{~V} ;(\mathbf{b})$ when $V_{d c}=11 \mathrm{~V}$.

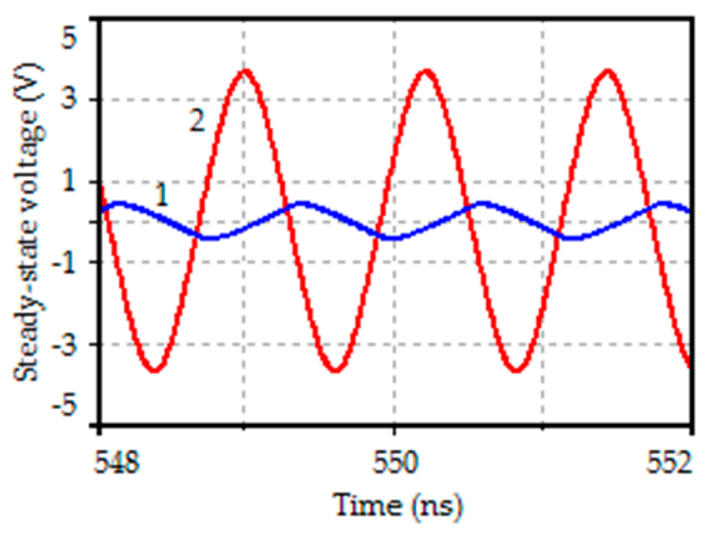

(a)

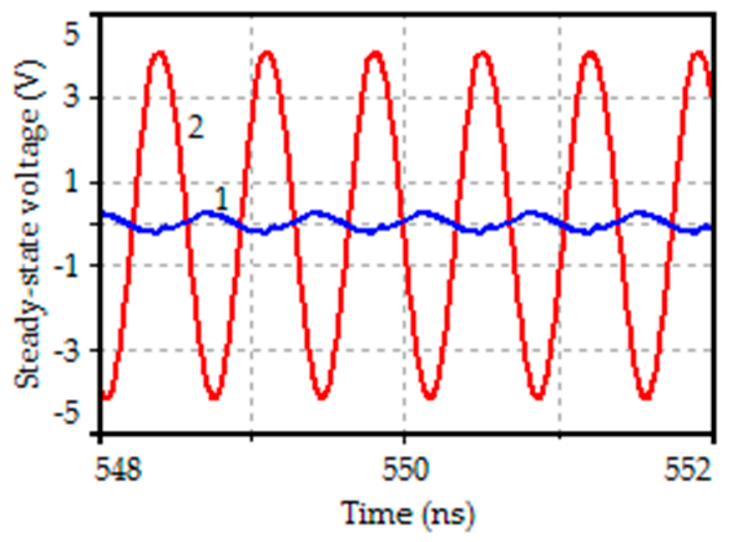

(b)

Figure 9. Steady-state voltages at nodes 1 and 2; (a) when $V_{d c}=1 \mathrm{~V},(\mathbf{b})$ when $V_{d c}=11 \mathrm{~V}$.

Therefore, the loaded quality factor can be calculated by the following equation:

$$
Q_{L}=I_{\text {tank }} / I_{\text {res }}
$$

By simulation, we find that $I_{\text {tank }}=127 \mathrm{~mA}$ and $I_{\text {res }}=15 \mathrm{~mA}$. Substituting the currents into (30) gives that $Q_{L}=8.5$. Further, by substitution of $V_{\text {triangle }}$ and $Q_{L}$ into Equation (21), we calculate that $\left|V_{\text {out }, 1}\right|=2.76 \mathrm{~V}$. So, the relative error of amplitude calculation by Equation (21) is only $13.5 \%$.

Figure 10b shows the VCO tuning characteristics. As we can see in Figure 10b, the VCO operates from $830 \mathrm{MHz}$ to $1.429 \mathrm{GHz}$, i.e., the tunable band is $599 \mathrm{MHz}$. Thus, the designed circuit is a wideband $\mathrm{VCO}$, which operates in the frequency range, significantly exceeding the bandwidth of the OPA. Indeed, the bandwidth of the LMH6629MF is $900 \mathrm{MHz}$, but the highest VCO frequency is $1.429 \mathrm{GHz}$. Using the equation for maximum signal frequency [12], we can find that with the OPA LMH6629MF in the Colpitts or Hartley VCO, the $4 \mathrm{~V}$ amplitude of the sinusoidal voltage corresponds to a frequency that is less than $64 \mathrm{MHz}$. 


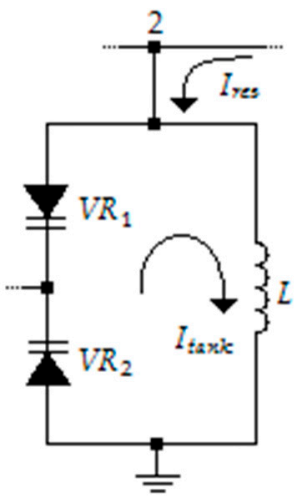

(a)

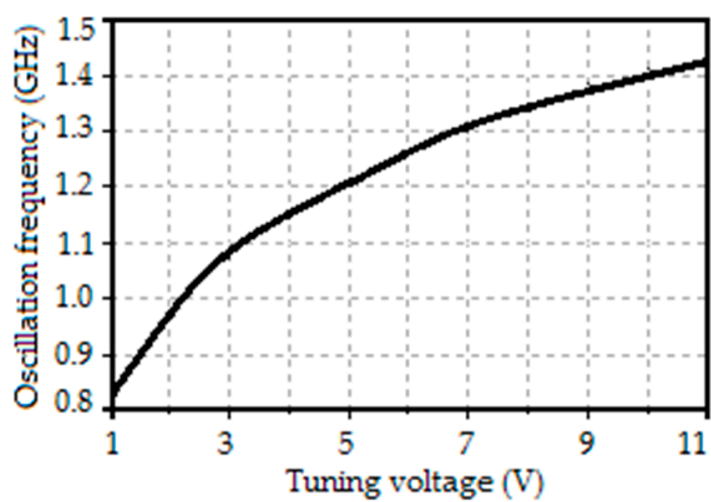

(b)

Figure 10. (a) Illustration of external and contour currents at resonance in the VCO tank circuit; (b) VCO tuning characteristics.

Thus, by using the proposed VCO topology, we can increase the maximum operating frequency by more than 22 times. Figure 11 shows the simulated power spectrum of the designed VCO at the lowest frequency (a) and the highest frequency (b). As we can see in Figure 11a, only the second and third harmonics contribute to the THD because the fourth and subsequent harmonics attenuated for at least $90 \mathrm{~dB}$ compared to the first harmonic. By analyzing Figure $11 \mathrm{~b}$, we find that the second and upper harmonics decrease slowly. However, the second and other harmonics attenuated by at least $36 \mathrm{~dB}$.

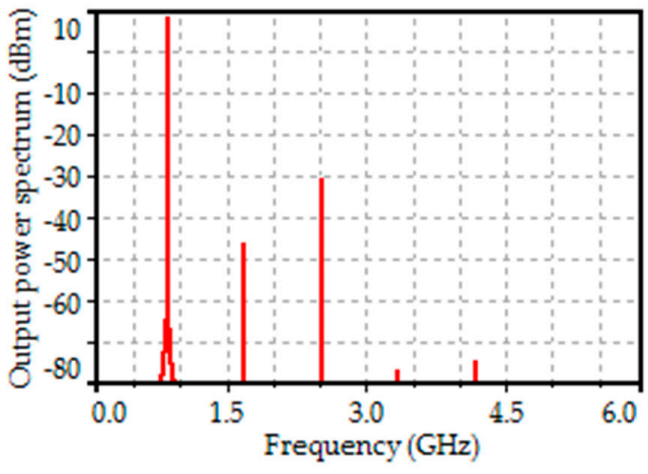

(a)

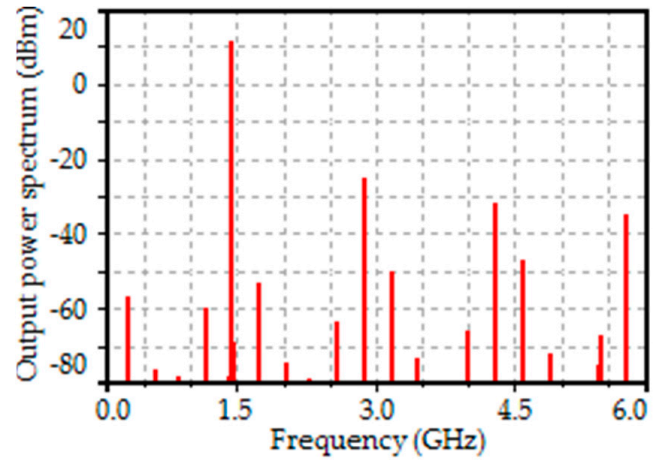

(b)

Figure 11. Output power spectrum (a) when $V_{d c}=1 \mathrm{~V} ;(\mathbf{b})$ when $V_{d c}=11 \mathrm{~V}$.

One of the essential characteristics of an oscillator operating at microwave frequencies is phase noise. To calculate the phase noise of the simulated VCO, we use the improved Leeson's formula [25] (p. 128)

$$
P N\left(f_{m}\right)=10 \log \left\{\frac{F k T}{2 P_{\text {out }}}\left[\frac{f_{\text {fun }}^{2} f_{c}}{f_{m}^{3} 4 Q_{L}^{2}}+\left(\frac{f_{f u n}}{2 Q_{L} f_{m}}\right)^{2}+\left(1+\frac{f_{c}}{f_{m}}\right)\right]\right\}
$$

where $P N$ is the phase noise $(\mathrm{dBc} / \mathrm{Hz}), F$ is the noise figure of the oscillator active device $(\mathrm{dB})$, $k \approx 1.38 \times 10^{-23}$ is the Boltzmann constant $(\mathrm{J} / \mathrm{K}), T$ is the temperature in Kelvin, $P_{\text {out }}$ is the oscillator output power, $f_{\text {fun }}$ is the frequency of oscillations $(\mathrm{Hz}), f_{\mathcal{c}}$ is the $1 / f$ corner frequency of active device $(\mathrm{Hz})$, and $f_{m}$ is the offset frequency $(\mathrm{Hz})$.

According to Reference [7], the noise figure of OPA LMH6629MF is $8 \mathrm{~dB}$. Figure 11a,b shows that $P_{\text {out }}=9 \mathrm{dBm}$ when $V_{d c}=1 \mathrm{~V}$ and $P_{\text {out }}=11 \mathrm{dBm}$ when $V_{d c}=11 \mathrm{~V}$. Figure $10 \mathrm{~b}$ indicates that the minimum frequency of oscillations is $830 \mathrm{MHz}$, and the maximum is $1429 \mathrm{MHz}$. From Reference [7] 
(p.15, Figure 28) we find that $f_{c}=4 \mathrm{kHz}$. The loaded quality factor, $Q_{\mathrm{L}}$, is 8.5 and 2.6 for $V_{d c}=1 \mathrm{~V}$ and $11 \mathrm{~V}$, respectively.

Figure 12 shows the dependence of the phase noise versus offset frequency for the VCO shown in Figure 7. As can be seen in Figure 12, the VCO phase noise changes from $-153.4 \mathrm{dBc} / \mathrm{Hz}$ to $-139.3 \mathrm{dBc} / \mathrm{Hz}$ at $100 \mathrm{kHz}$ offset frequency when the control voltage varies from $1 \mathrm{~V}$ to $11 \mathrm{~V}$. Thus, the maximum in-band phase noise is $-139.3 \mathrm{dBc} / \mathrm{Hz}$ at $f_{m}=100 \mathrm{kHz}$.

Let us compare the characteristics of the simulated VCO with the best VCO designs operating in the microwave frequency range. The commonly used FoM includes phase noise $(P N)$, the ratio of $f_{f u n}$ to $f_{m}$, and the power consumption $\left(P_{c}\right)$ [26].

$$
\operatorname{FoM}\left(f_{m}\right)=P N\left(f_{m}\right)_{d B c}-20 \log \left(f_{f u n} / f_{m}\right)+10 \log \left(P_{c} / 1 \mathrm{~mW}\right)
$$

In Equation (32), the second term allows one to compare the phase noise of the oscillators determined at different frequencies and various frequency offsets. The third term in (32) has a positive sign if $P_{c}>1 \mathrm{~mW}$ and negative if $P_{c}<1 \mathrm{~mW}$. Thus, the smaller the value of FoM, the higher efficiency of the oscillator.

Table 1 shows a comparison of the designed VCO with microwave oscillators that have been reported in journals and conference proceedings.

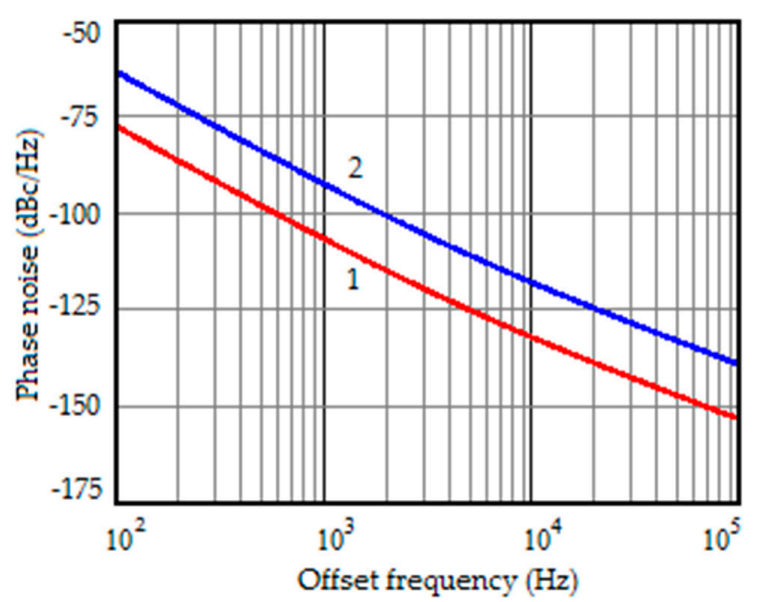

Figure 12. Phase noise versus offset frequency when $V_{d c}=1 \mathrm{~V}$ (curve 1 ) and $V_{d c}=11 \mathrm{~V}$ (curve 2).

Table 1. Comparison of designed VCO to other published microwave oscillators.

\begin{tabular}{ccccccc}
\hline VCO & Technology & $\begin{array}{c}\text { Frequency } \\
\text { GHz }\end{array}$ & $\begin{array}{c}\text { Frequency } \\
\text { Offset } \mathbf{M H z}\end{array}$ & $\begin{array}{c}\text { Phase Noise } \\
\mathbf{d B c} / \mathbf{H z}\end{array}$ & $\begin{array}{c}\text { Power } \\
\text { Consumption MW }\end{array}$ & FoM dBc/Hz \\
\hline$[27]$ & GaN HEMT & 4.7 & 1 & -121.7 & 2.7 & -190 \\
{$[28]$} & SiGe & 29.8 & 1 & -115 & 37 & -185 \\
{$[29]$} & HEMT & 11.2 & 1 & -97 & 0.09 & -188 \\
{$[30]$} & SiGe & $6.5 \div 15.1$ & 1 & -110 & 19 & -177 \\
{$[31]$} & GaN HEMT & $6.5 \div 7.5$ & 1 & -110 & 50 & -170 \\
{$[32]$} & GaN HEMT & 8.82 & 1 & -124.95 & 21.6 & -190.5 \\
{$[33]$} & GaN HEMT & 7.26 & 1 & -122.48 & 18.33 & -187 \\
{$[34]$} & GaN HEMT & 1.95 & 1 & -149 & 400 & -189 \\
{$[35]$} & GaN HEMT & 5.2 & 1 & -125.7 & 16 & -182.7 \\
{$[36]$} & GaAs pHEMT & 37.608 & 1 & -112.31 & 130 & -179.5 \\
{$[37]$} & SiGe BJT & 2.4 & 1 & -128 & 41 & -183.9 \\
{$[38]$} & CMOS & 26.5 & 1 & -105.8 & 10.8 & -202 \\
{$[39]$} & CMOS & 1.61 & 0.1 & -121 & 2.7 & -198.6 \\
{$[40]$} & CMOS & 11.58 & 1 & -112.62 & 6 & -204 \\
{$[41]$} & CMOS & 8 & 1 & -134.3 & 6.6 & -198.6 \\
\hline This work & SiGe & 1.429 & 0.1 & -139.3 & 240 & \\
\hline
\end{tabular}


We can see in Table 1 that the designed VCO has the best FoM among oscillators fabricated in GaN HEMT, SiGe, HEMT, GaAs pHEMT, and SiGe BJT technologies where, in general, power consumption is high enough. Moreover, as shown in Table 1, the designed VCO can even compete with the latest achievements in CMOS VCOs; this is due to low phase noise and in spite of higher power dissipation.

\section{Experimental Results}

We fabricated a prototype of oscillator circuit shown in Figure 2b. Figure 13 shows a PCB assembly of the oscillator. We selected OPA LMH6624 (Texas Instruments) with a slew rate of $350 \mathrm{~V} / \mu \mathrm{s}$, gain bandwidth of $1.5 \mathrm{GHz}$, supply voltage $\pm 5 \mathrm{~V}$, and the following passive components: $L_{0}=200 \mathrm{nH}\left(2 \times\right.$ ELJRFR10), $L=8.2 \mathrm{nH}$ (high-quality coil ELJQF8N2), and $C_{1}=2.2 \mathrm{pF}$ (ceramic capacitor C0603C0G1E2R2C030BA). We removed varactors $V R_{1}$ and $V R_{2}$, and inductor $L_{2}$ from the oscillator circuit for simplicity, i.e., $C_{V R 1}=C_{V R 2}=0$, and $L_{2}=\infty$.

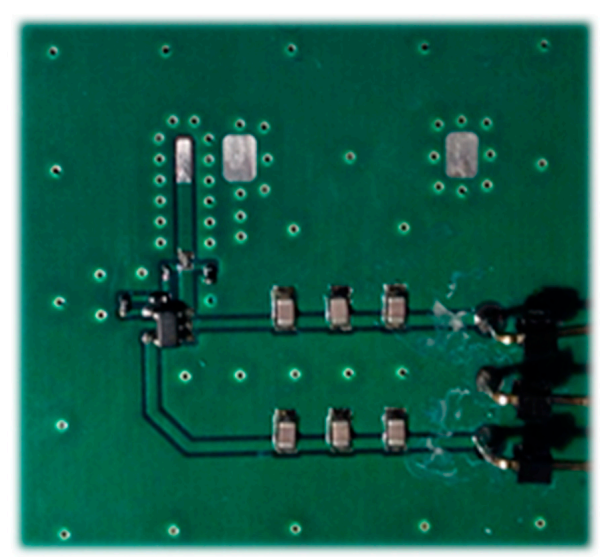

Figure 13. Printed circuit board assembly of fabricated oscillator.

A spectrum analyzer USB-SA44B (Keysight Technologies) was used to measure the output power spectrum. We used RF probes P-20A (Auburn Technology) to connect the oscillator output through a capacitive divider to the spectrum analyzer. Figure 14 shows the block diagram of the measurement experiment.

Figure 15 shows the connection between the core elements of the measurement block diagram. The 2-channel power supply HMC8042-G (Rohde and Schwarz) is not shown in Figure 15.

Figure 16 shows the measured power spectrum. As we can see in Figure 16, the frequency of oscillations is $583.1 \mathrm{MHz}$. The measured power is $-43.9 \mathrm{dBm}$. However, in estimating the real output power, we should consider $21 \mathrm{~dB}$ probes attenuation, $10 \mathrm{~dB}$ "Attenuation" setting in the spectrum analyzer, and $13 \mathrm{~dB}$ insertion loss of the capacitive divider. Thus, the actual power at the output of the fabricated oscillator was around $0 \mathrm{dBm}$.

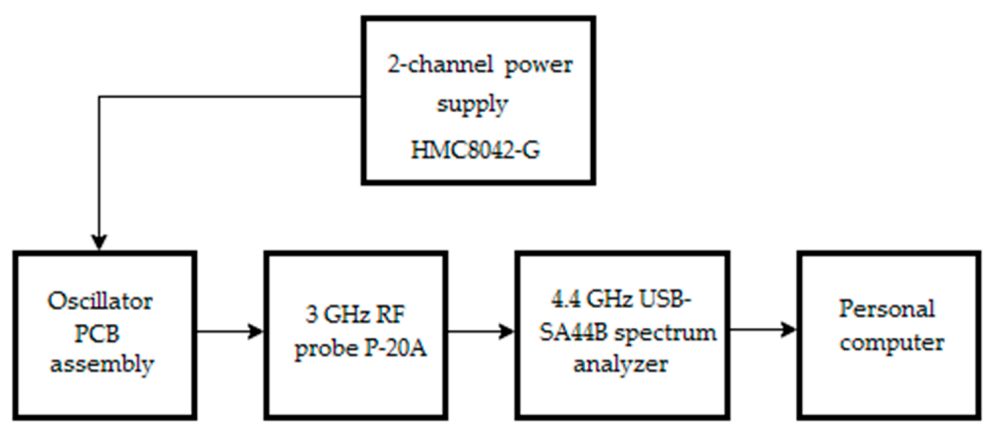

Figure 14. Block diagram of the measurement experiment. 


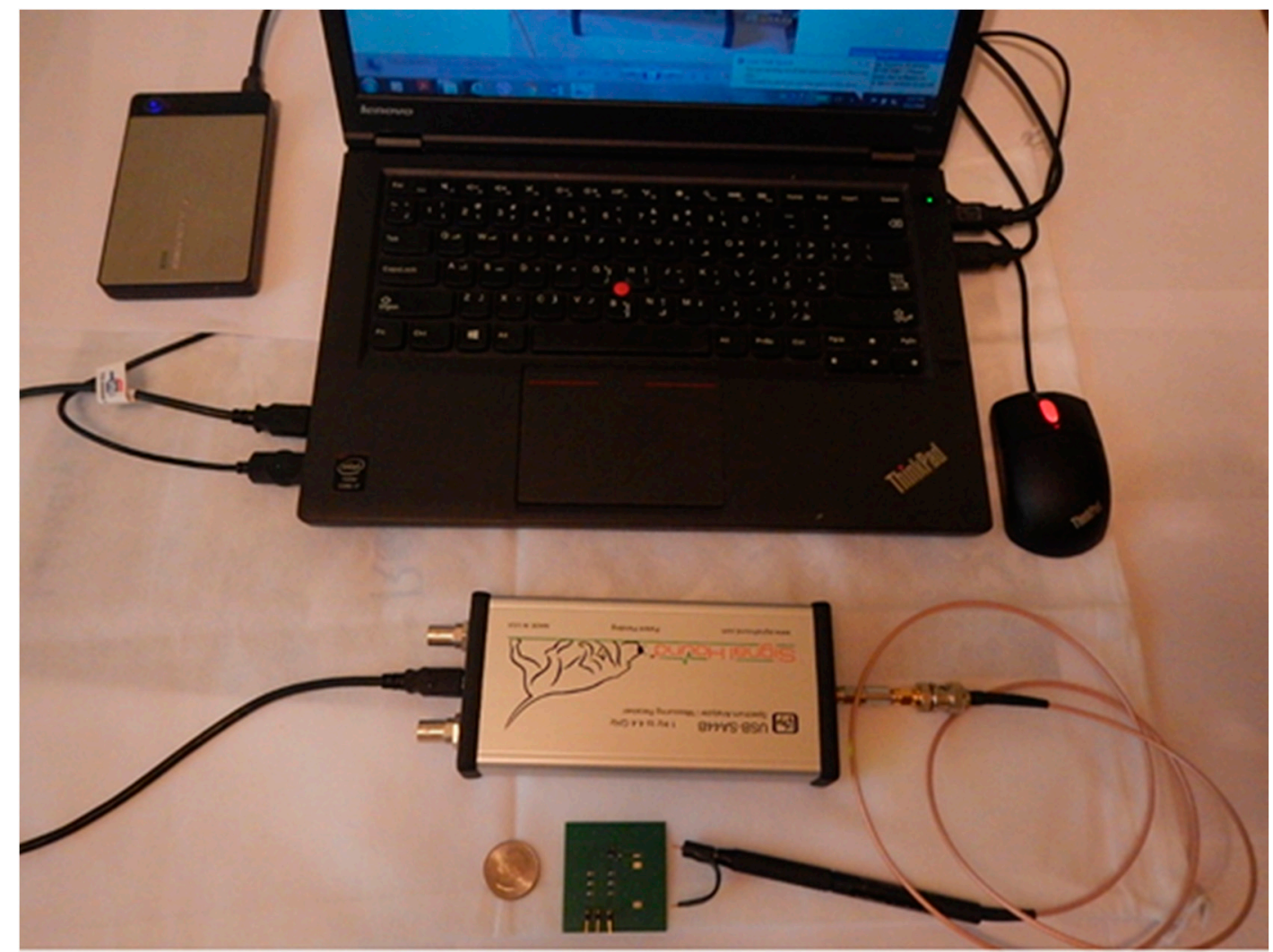

Figure 15. Photograph of the test set-up except for the 2-channel power supply.

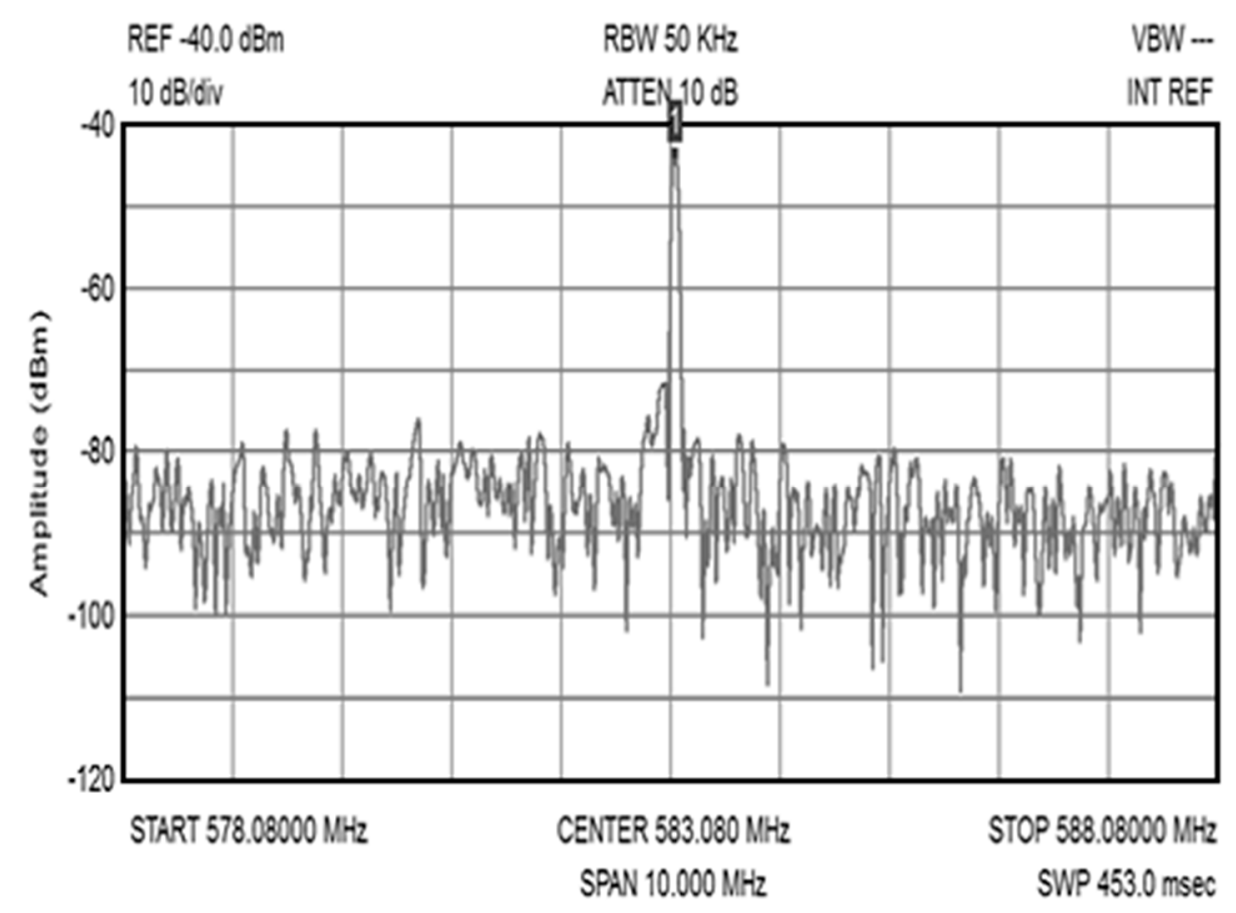

Marker 1: $583.1256 \mathrm{MHz},-43.9 \mathrm{dBm}$

Figure 16. Measured output power spectrum over $10 \mathrm{MHz}$ span and RBW $=50 \mathrm{kHz}$. 


\section{Conclusions}

This article has proposed a new type of VCO based on resistorless negative impedance converter circuits. A distinctive feature of each proposed VCO circuit is that its output is located at the noninverting input of the OPA; this allows us to significantly increase the frequency and amplitude of the generated oscillations. Mathematical modeling of the amplitude of the oscillations and the start-up conditions were carried out. We have shown that, unlike existing oscillators of the Colpitts and Hartley topology, in the proposed VCO, the gain is less than unity, and the feedback coefficient is greater than unity. Therefore, the proposed oscillators can operate at frequencies exceeding the unity-gain bandwidth. The advantage of the proposed VCO circuit is also the fact that the amplitude of the generated sinusoidal oscillations can be dozens of times higher than the magnitude of the nonsinusoidal oscillations at the output of the OPA. The designed and simulated VCO uses $\pm 5 \mathrm{~V}$ supply voltage and operates in a wide frequency range from $830 \mathrm{MHz}$ to $1429 \mathrm{MHz}$ showing a maximum in-band THD of $1.7 \%$ while the OPA bandwidth is only $900 \mathrm{MHz}$; the amplitude of oscillations varies from $3.2 \mathrm{~V}$ to $4 \mathrm{~V}$. It has a maximum in-band phase noise of $-139.3 \mathrm{dBc} / \mathrm{Hz}$ at $100 \mathrm{kHz}$ offset frequency and has an outstanding value of FoM of $-198.6 \mathrm{dBc} / \mathrm{Hz}$. The conducted comparison of the designed VCO with VCOs in previously published studies concerning standard FoM has shown that the proposed oscillator is about 8-15 dB more efficient than the GaN HEMT, GaN pHEMT, HEMT, and SiGe VCOs and close to the best CMOS VCOs. We have shown that for the same OPA, the operating frequency of the proposed VCO is 22 times higher than that of the Colpitts and Hartley oscillators. The fabricated prototype-oscillator based on OPA LMH6624 operates at a frequency of $583.1 \mathrm{MHz}$ with a power level of $0 \mathrm{dBm}$.

The proposed OPA VCO circuits are easy to design. They do not require settings during the manufacturing process. These oscillators can be used from high-frequency to the microwave frequency range. Since the power consumption in the proposed VCO is higher than in the CMOS oscillators, the field of application extends to communications, navigation, and radar equipment with an uninterruptible power supply line. As the proposed schemes do not require tuning, they can be useful in conducting laboratory works in the departments of electronics at universities.

Our future work will include mathematical modeling of phase noise in the proposed oscillators using the method of impulse sensitivity functions.

Author Contributions: This article presents the collective work of two authors. The authors (A.R. and V.U.) jointly participated in the conceptualization of the problem, development of oscillator circuits and mathematical modeling, numerical calculations, and writing the article. V.U. participated in prototype oscillator design and fabrication. A.R. conducted project administration. All authors have read and agreed to the published version of the manuscript.

Funding: This research received no external funding.

Acknowledgments: The authors express thanks to engineer A. Kolesnik for technical support.

Conflicts of Interest: The authors declare no conflict of interest.

\section{Nomenclature}

$Z_{\text {in }} \quad$ Input impedance seen by the noninverting terminal of OPA

$Z_{0} \quad$ Impedance between the inverting input and output of OPA

$Z_{1} \quad$ Impedance between the noninverting input and output of OPA

$Z_{2} \quad$ Impedance between the inverting input of OPA and ground

$L \quad$ Inductor of the tank circuit

$V R_{1}$ and $V R_{2} \quad$ Varactors of the tank circuit

$R_{d c} \quad$ Resistor isolating the dc control voltage line from the VCO tank

$L_{1} \quad$ Positive feedback inductor

$C_{1} \quad$ Positive feedback capacitor

$L_{0} \quad$ Negative feedback inductor 
$C_{0} \quad$ Negative feedback capacitor

$L_{2} \quad$ Inductor between inverting terminal of OPA and ground

$\mathrm{C}_{\mathrm{VCO}} \quad$ VCO total capacitance

$L_{V C O} \quad$ VCO total inductance

$C_{O P A} \quad$ Input capacitance of OPA

$C_{P C B} \quad$ Parasitic capacitance of PCB

$C_{V R 1} \quad$ Capacitance of varactor $V R_{1}$

$C_{V R 2} \quad$ Capacitance of varactor $V R_{2}$

$y_{11}$

$i_{O P A}(t)$

$v_{\text {out }}(t)$

Input admittance of feedback network

$I_{O P A, 1}$

Feedback current flowing through impedance $Z_{1}$

Output voltage of VCO

$\omega_{f u n}$

Complex amplitude of the first harmonic of current $i_{O P A}(t)$

$\varphi_{1}$

Angular frequency of the first (fundamental) harmonic of current $i_{O P A}(t)$

$R_{\text {par }}$

Phase of the first harmonic of current $i_{O P A}(t)$

$V_{\text {sat }}$

Equivalent parallel resistance of the tank circuit at the fundamental frequency

Saturation voltage of OPA

$R_{C}$

Load resistor connected between OPA output and tank circuit in the Colpitts and

Hartley oscillators

$v_{O P A}(t) \quad$ Voltage at the output of OPA (node 1)

$V_{\mu}$

$\left|V_{\mu}\right|$

Complex amplitude of harmonic number $\mu$ of voltage $v_{O P A}(t)$

$\theta_{\mu} \quad$ Phase of harmonic number $\mu$ of voltage $v_{O P A}(t)$

$V_{\text {triangle }} \quad$ Amplitude of triangular voltage at OPA output

$I_{O P A, \mu}$

Complex amplitude of current harmonic number $\mu$

$\left|I_{O P A, \mu}\right| \quad$ Amplitude of current harmonic number $\mu$

$\varphi_{\mu} \quad$ Phase of current harmonic number $\mu$

$\rho \quad$ Tank circuit characteristic impedance

$r_{s} \quad$ Series loss resistance of the tank circuit

$Q \quad$ Quality factor of the parallel tank circuit

$Q_{L} \quad$ Quality factor of the loaded parallel tank circuit

$|A| \quad$ Gain of impedance converter

$|\beta| \quad$ Gain of feedback network

$\varphi_{A} \quad$ Initial phase of impedance converter

$\varphi_{\beta} \quad$ Initial phase of feedback network

$\left|V_{1}\right| \quad$ Voltage amplitude of the first harmonic of triangular voltage at the output of OPA (node 1)

$I_{\text {tank }} \quad$ Current circulating in the tank circuit at resonance

$I_{\text {res }} \quad$ External current entering the tank circuit at resonance

FoM Figure of merit

$P_{c} \quad$ Power consumption of oscillator

$P N \quad$ Phase noise

$P_{\text {out }} \quad$ Oscillator output power

$F \quad$ Noise figure

$k \quad$ Boltzmann constant

$T \quad$ Temperature in Kelvin

$f_{c} \quad 1 / \mathrm{f}$ corner frequency

$f_{m} \quad$ Offset frequency

$f_{\text {fun }} \quad$ Frequency of oscillations in $\mathrm{Hz}$

\section{Abbreviations}

The following abbreviations exist in the manuscript: 


$\begin{array}{ll}\text { AC } & \text { Alternating current } \\ \text { BJT } & \text { Bipolar junction transistor } \\ \text { CMOS } & \text { Complementary metal-oxide-semiconductor } \\ \text { FoM } & \text { Figure of merit } \\ \text { GaAs } & \text { Gallium arsenide } \\ \text { GaN } & \text { Gallium nitride } \\ \text { HBT } & \text { Heterojunction bipolar transistor } \\ \text { HEMT } & \text { High-electron-mobility transistor } \\ \text { OPA } & \text { Operational amplifier } \\ \text { PCB } & \text { Printed circuit board } \\ \text { pHEMT } & \text { Pseudomorphic high-electron-mobility transistor } \\ \text { RF } & \text { Radio frequency } \\ \text { SiGe } & \text { Silicon germanium } \\ \text { SPICE } & \text { Simulation program with integrated circuit emphasis } \\ \text { THD } & \text { Total harmonic distortion } \\ \text { VCO } & \text { Voltage controlled oscillator }\end{array}$

\section{References}

1. Schulz:, M.; Strobel, A.; Ellinger, F. System considerations and VCO design for a local positioning system at $2.4 \mathrm{GHz}$ for rescue of people on ships and in sea. In Proceedings of the IEEE 10th Workshop on Positioning, Navigation and Communication (WPNC), Dresden, Germany, 20-21 March 2013. [CrossRef]

2. Carlowitz, C.; Esswein, A.; Weigel, R.; Vossiek, M. A low power pulse frequency modulated UWB radar transmitter concept based on switched injection-locked harmonic sampling. In Proceedings of the 7th German Microwave Conference, Ilmenau, Germany, 12-14 March 2012.

3. Scherbina, K.A.; Pechenin, V.V.; Vonsovitch, M.A. Phase-locked loop combined system of voltage controlled oscillator. In Proceedings of the IEEE 9th International Kharkiv Symposium on Physics and Engineering of Microwaves, Millimeter and Submillimeter Waves (MSMW), Kharkiv, Ukraine, 20-24 June 2016. [CrossRef]

4. Grebennikov, A. RF and Microwave Transistor Oscillator Design; John Wiley \& Sons, Ltd.: Chichester, UK, 2007. [CrossRef]

5. Gonzalez, G. Foundations of Oscillator Circuit Design; Artech House: Boston, MA, USA, 2007.

6. Everard, J. Fundamentals of RF Circuit Design: With Low Noise Oscillators; John Wiley\& Sons, Ltd.: Chichester, UK, 2001. [CrossRef]

7. LMH6629 Ultra-Low Noise, High-Speed Operational Amplifier with Shutdown Datasheet (Rev. I). Available online: http://www.ti.com/lit/ds/symlink/lmh6629.pdf (accessed on 1 December 2014).

8. Ulansky, V.; Machalin, I.; Tkalich, O. Analysis and design of voltage-controlled oscillators using high-speed operational amplifiers. Proc. Natl. Aviat. Univ. 2002, 3, 171-178. [CrossRef]

9. Ulansky, V.V.; Kolesnik, A.A.; Elsherif, H.M. A new high-performance OPA based VCO for microwave applications. In Proceedings of the 2014 IEEE Microwaves, Radar and Remote Sensing Symposium, Kiev, Ukraine, 23-25 September 2014. [CrossRef]

10. Rashid, M.H. Microelectronic Circuits. Analysis and Design; Cengage Learning: Stamford, CT, USA, 2011; p. 883.

11. Jacas, M.M.; Llopis, F. LC sine-wave oscillators using general-purpose voltage operational-amplifiers. Int. J. Electr. Eng. Educ. 2007, 44, 244-248. [CrossRef]

12. Boylestad, R.; Nashelsky, L. Electronic Devices and Circuit Theory, 11th ed.; Pearson: Boston, MA, USA, 2011; p. 619.

13. Ulansky, V.V.; Elsherif, H.M. A voltage-controlled oscillator based on negative inductance converter. In Proceedings of the IEEE 35th International Conference on Electronics and Nanotechnology (ELNANO), Kyiv, Ukraine, 21-24 April 2015. [CrossRef]

14. Chen, W.K. The Circuits and Filters Handbook; CRC Press: New York, NY, USA, 2003; pp. 396-397.

15. Horowitz, P.; Hill, W. The Art of Electronics, 2nd ed.; Cambridge University Press: Cambridge, UK, 1989; pp. 266-267. [CrossRef]

16. Beck, B.S.; Cunefare, K.A.; Collet, M. The power output and efficiency of a negative capacitance shunt for vibration control of a flexural system. Smart Mater. Struct. 2013, 22, 1-10. [CrossRef] 
17. Negative Impedance Converter. Available online: https://en.wikipedia.org/wiki/Negative_impedance_ converter (accessed on 13 April 2020).

18. Savant, C.J.; Roden, M.S.; Carpenter, G.L. Electronic Design. Circuits and Systems, 2nd ed.; The Benjamin/Cummings Publishing Company, Inc.: Redwood City, CA, USA, 1991.

19. Johnson, J.B. Thermal agitation of electricity in conductors. Phys. Rev. 1928, 32, 97. [CrossRef]

20. Nilson, J.W.; Riedel, S.A. Electric Circuits, 5th ed.; Addison Wesley: New York, NY, USA, 1996; pp. 791, 806-809.

21. Boylestad, R.L. Introductory Circuit Analysis, 10th ed.; Pearson Education: London, UK, 2002.

22. Jaeger, R.C.; Blalock, T.N. Microelectronic Circuit Design, 4th ed.; McGraw-Hill Education: New York, NY, USA, 2010; p. 1449.

23. Rhea, R.W. Oscillator Design and Computer Simulation; Noble Publishing Corp.: Atlanta, GA, USA, 1996. [CrossRef]

24. Advanced XTAL Products. Available online: https:/www.axtal.com/cms/docs/doc101437.pdf (accessed on 19 August 2016).

25. Rohde, U.L.; Poddar, A.K.; Bock, G. The Design of Modern Microwave Oscillators for Wireless Applications: Theory and Optimization; John Wiley \& Sons, Inc.: New Jersey, NJ, USA, 2005. [CrossRef]

26. Hegazi, E.; Sjoland, H.; Abidi, A. A filtering technique to lower LC oscillator phase noise. IEEE J. Sol.-St. Circ. 2001, 36, 1921-1930. [CrossRef]

27. Jang, S.-L.; Su, Y.-J.; Lin, K.J.; Wang, B.-J. An 4.7 GHz low power cross-coupled GaN HEMT oscillator. Microw. Opt. Technol. Lett. 2018, 60, 2442-2447. [CrossRef]

28. Hollmann, A.; Jirovec, D.; Kucharski, M.; Kissinger, D.G.; Fischer, G.; Schreiber, L.R. 30 GHz-voltage controlled oscillator operating at 4 K. Rev. Sci. Instrum. 2018, 89. [CrossRef] [PubMed]

29. Matheoud, A.V.; Solmaz, N.S.; Boero, G. A low-power microwave HEMT LC oscillator operating down to 1.4 K. IEEE Trans. Microw. Theory Tech. 2019, 67, 2782-2792. [CrossRef]

30. Drechsel, T.; Joram, N.; Ellinger, F. A 6.5 to $15.1 \mathrm{GHz}$ ultra-wideband SiGe LC VCO with 80\% continuous tuning range. In Proceedings of the Eur. Conf. Circuit Theory Design (ECCTD), Catania, Italy, 4-6 September 2017. [CrossRef]

31. Kong, C.; Li, H.; Chen, X.; Jiang, S.; Zhou, J.; Chen, C. A monolithic AlGaN/GaN HEMT VCO using BST thin-film varactor. IEEE Trans. Microw. Theory Tech. 2012, 60, 3413-3419.

32. Jang, S.L.; Chang, Y.-H.; Chiou, J.-S.; Lai, W.-C. A single GaN HEMT oscillator with four-path inductors. In Proceedings of the 2018 7th International Symposium on Next Generation Electronics (ISNE), Taipei, Taiwan, 7-9 May 2018. [CrossRef]

33. Jang, S.-L.; Chang, Y.-H.; Lai, W.-C. A feedback GaN HEMT oscillator. In Proceedings of the 2018 IEEE International Conference on Microwave and Millimeter Wave Technology (ICMMT), Chengdu, China, 7-11 May 2018. [CrossRef]

34. Lai, S.; Kuylenstierna, D.; Ozen, M.; Horberg, M.; Rorsman, N.; Angelov, I.; Zirath, H. Low phase noise GaN HEMT oscillators with excellent figures of merit. IEEE Microw. Wirel. Compon. Lett. 2014, 24, 412-414. [CrossRef]

35. Lai, W.-C.; Jang, S.-L.; Chen, Y.-W. Dual-feedback GaN HEMT oscillator. In Proceedings of the 2019 IEEE International Symposium on Radio-Frequency Integration Technology (RFIT), Nanjing, China, 28-30 August 2019. [CrossRef]

36. Chang, C.-L.; Tseng, C.-H.; Chang, H.-Y. A new monolithic Ka-band filter-based voltage-controlled oscillator using $0.15 \mu \mathrm{m}$ GaAs pHEMT technology. IEEE Microw. Wirel. Compon. Lett. 2014, 24, 111-113. [CrossRef]

37. Lai, P.W.; Dobos, L.; Long, S. A $2.4 \mathrm{GHz}$ SiGe low phase-noise VCO using on chip tapped inductor. In Proceedings of the 29th European Solid-State Circuits Conference, Estoril, Portugal, 16-18 September 2003. [CrossRef]

38. Fu, Y.; Li, L.; Wang, D.; Wang, X.; He, L. 28-GHz CMOS VCO with capacitive splitting and transformer feedback techniques for $5 \mathrm{G}$ communication. IEEE Trans. Very Large Scale Integr. (VLSI) Syst. 2019, 27, 2088-2095. [CrossRef]

39. Cai, H.L.; Yang, Y.; Qi, N.; Chen, X.; Tian, H.; Song, Z.; Xu, Y.; Zhou, C.; Zhan, J.; Wang, A.; et al. A $2.7-\mathrm{mW} 1.36-1.86-\mathrm{GHz} \mathrm{LC}-\mathrm{VCO}$ with a FOM of $202 \mathrm{dBc} / \mathrm{Hz}$ enabled by a $26 \%$-size-reduced nano-particle-magnetic-enhanced inductor. IEEE Trans. Microw. Theory Tech. 2014, 62, 1221-1228. [CrossRef] 
40. Kim, S.J.; Seo, D.I.; Kim, J.S.; Song, R.; Kim, B.S. Compact CMOS LiT VCO achieving 198.6 dBc/Hz FoM. Electron. Lett. 2018, 54, 175-177. [CrossRef]

41. Zailer, E.; Belostotski, L.; Plume, R. 8-GHz, 6.6-mW LC-VCO with small die area and FOM of $204 \mathrm{dBc} / \mathrm{Hz}$ at 1-MHz offset. IEEE Microw. Wirel. Compon. Lett. 2016, 26, 936-938. [CrossRef]

(C) 2020 by the authors. Licensee MDPI, Basel, Switzerland. This article is an open access article distributed under the terms and conditions of the Creative Commons Attribution (CC BY) license (http://creativecommons.org/licenses/by/4.0/). 